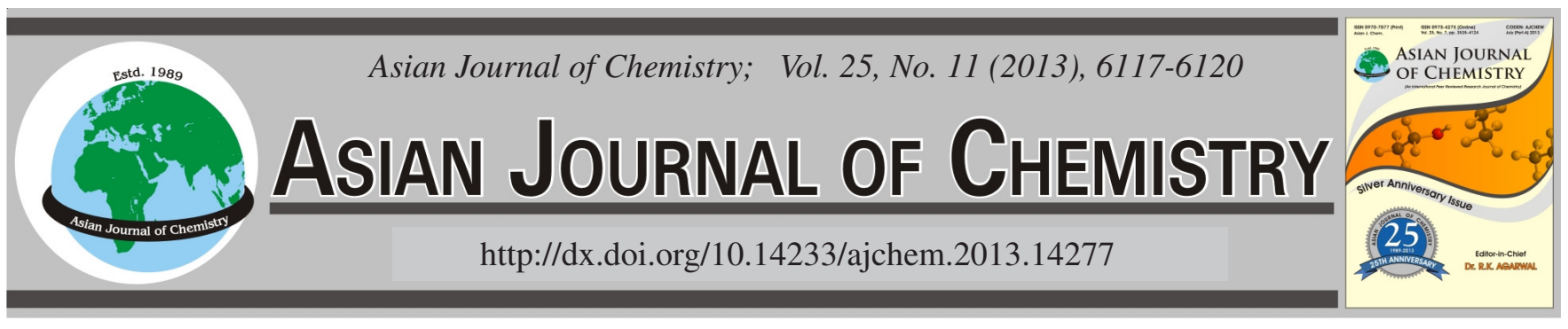

\title{
Iron Powder Promoted Regio-Selective Friedel-Crafts Acylation of Indole Under Solvent-Free Conditions
}

\author{
LiRong Zhang, FengPing Yi ${ }^{*}$, JianZhong Zou and Shaoyan Qu
}

School of Perfume and Aroma Technology, Shanghai Institute of Technology, Shanghai 201418, P.R. China

*Corresponding author: Tel: +86 21 60873280; E-mail: yifengping@ sit.edu.cn; zlir2008@163.com

A facile, efficient and environment-friendly protocol for the regioselective synthesis of 3-acyl indoles has been developed by one-pot catalytic Friedel-Crafts acylation of indole in presence of the iron powder as catalyst under solvent-free conditions at room temperature.

Key Words: Friedel-Crafts acylation, Indole, Iron powder, Solvent free.

\section{INTRODUCTION}

The indole moiety is present in a range of pharmaceutical materials and the synthesis of 3-acyl indoles has gained considerable attention. 3-Substituted indoles are not only significant therapeutic agents but also used as synthetic intermediates in alkaloid synthesis ${ }^{1,2}$. Various synthetic methods are reported in the literature for 3-substituted indoles ${ }^{3-13}$. The common method to prepare 3-acyl indoles is Friedel-Crafts reaction under acidic conditions, which resulting in the side reactions caused from high nucleophilic nature of indole ${ }^{6-13}$. Hence, several efforts have also been made to reduce the competing side reactions ${ }^{10-12}$. On the other hand, the development of suitable catalysts for the facile synthesis of 3-acyl indoles without $\mathrm{NH}$-protection has attracted much attention. Lewis acids such as alkyl aluminium chloride ${ }^{8,9}$ imidazolium chloroaluminate ${ }^{6}$, $\mathrm{SnCl}_{4}{ }^{7}$ as well as $\mathrm{ZrCl}_{4}{ }^{13}$ have been reported as the promoters. Iron(III) oxide promoting aromatic Friedel-Crafts acylation have been known ${ }^{14}$. We speculated that iron containing compound could play a required role and be beneficial in selective acylaltion of indole.

Although numerous methods to achieve Friedel-Crafts acylation of indole are known, newer methods continue to attract attention for their experimental simplicity and effectiveness. A surface reaction may be more desirable than a solution counterpart, because the reaction is more convenient to run or a high yield of product is attained. For these reasons, surface synthetic organic chemistry is a rapidly growing field of study. It was also shown that zinc powder promotes the acylation of activated and unactivated aromatics under microwave irradiation $^{15}$. We have now discovered that iron powder alone promotes an efficient regioselective Friedel-Crafts acylation of indole with acyl chlorides in good to high yields under solvent free conditions in short reaction time. Therefore, in this paper we described a successful protocol for the synthesis of 3-acyl indoles catalyzed by iron powder.

\section{EXPERIMENTAL}

Chemicals were obtained from commercial suppliers and used without further purification. The NMR spectra were recorded on a BRUKER Avance III (500 $\mathrm{MHz}$ for $1 \mathrm{H})$ in deuterochloroform $\left(\mathrm{CDCl}_{3}\right)$ at room temperature. The chemical shift values are given in ppm and tetramethylsilane was used as an internal standard. Representative experimental procedure for the synthesis of 3-benzolylindole. To the iron powder (1.4 mmol, $85 \mathrm{mg}$ ) was dropped in benzoyl chloride (364 mg, $3 \mathrm{mmol}$ ) by a syring at rt under nitrogen, then indole ( $2 \mathrm{mmol}$, $234 \mathrm{mg}$ ) was added under a flow of nitrogen. After completion of the reaction as indicated by TLC $(1 \mathrm{~h})$, the resultant mixture was quenched with water $(10 \mathrm{~mL})$ and extracted with ethyl acetate $(3 \times 10 \mathrm{~mL})$. The combined organic layer was washed with water $(10 \mathrm{~mL})$, dried with anhydrous $\mathrm{Na}_{2} \mathrm{SO}_{4}$ and concentrated under vacuum. The column chromatographic purification of crude mass on silica gel eluting with EtOAc-petroleum ether provided the desired product.

All acylation reactions were carried out following representative procedure.

1H-indol-3-yl-phenylmethanone (3) ${ }^{13}$. White solid; m.p. 243-245 ${ }^{\circ} \mathrm{C}$; ${ }^{1} \mathrm{H} \mathrm{NMR}\left(\mathrm{CDCl}_{3}, 500 \mathrm{MHz}\right): \delta 8.26(\mathrm{~d}, J=7.5$ $\mathrm{Hz}, 1 \mathrm{H}), 7.93$ (s, 1H), 7.79 (d, J=7.5 Hz, 2H), 7.60 (d, $J=6.5$ $\mathrm{Hz}, 1 \mathrm{H}), 7.55$ (t, $J=7.5 \mathrm{~Hz}, 3 \mathrm{H}), 7.27-7.25$ (m, 2H).

1-Methyl- $1 H$-indol-3-yl-phenylmethanone $(4)^{13}$. White solid; m.p. $116-118{ }^{\circ} \mathrm{C} ;{ }^{1} \mathrm{H}$ NMR $\left(\mathrm{CDCl}_{3}, 500 \mathrm{MHz}\right)$ : $\delta 8.46-$ 
$8.45(\mathrm{~m}, 1 \mathrm{H}), 7.77(\mathrm{~d}, J=7.0 \mathrm{~Hz}, 2 \mathrm{H}), 7.52-7.48(\mathrm{~s}, 1 \mathrm{H})$, 7.45-7.41 (m, 3H), 7.32-7.29 (m, 3H), 3.88 (s, 3H).

(1H-Indol-3-yl)-(4-nitro-phenyl)-methanone (5) ${ }^{8}$. White solid; m.p. $234-237^{\circ} \mathrm{C}$; ${ }^{1} \mathrm{H} \mathrm{NMR}\left(\mathrm{CDCl}_{3}, 500 \mathrm{MHz}\right): \delta 8.50$ $(\mathrm{s}, 1 \mathrm{H}), 8.21(\mathrm{~d}, J=8.0 \mathrm{~Hz}, 1 \mathrm{H}), 8.02(\mathrm{~d}, J=8.0 \mathrm{~Hz}, 1 \mathrm{H}), 7.86$ $(\mathrm{s}, 1 \mathrm{H}), 7.52(\mathrm{~d}, J=8.0 \mathrm{~Hz}, 2 \mathrm{H}), 7.41(\mathrm{~d}, J=8.5 \mathrm{~Hz}, 1 \mathrm{H}), 7.35$ $(\mathrm{d}, J=8.5 \mathrm{~Hz}, 1 \mathrm{H}), 7.21(\mathrm{t}, J=6.5 \mathrm{~Hz}, 1 \mathrm{H}), 7.09(\mathrm{~d}, J=$ $8.0 \mathrm{~Hz}, 1 \mathrm{H})$.

(2-Methyl-1H-indol-3-yl)-phenyl-methanone $(\mathbf{6})^{13}$. White solid; m.p. $138-140{ }^{\circ} \mathrm{C} ;{ }^{1} \mathrm{H}$ NMR $\left(\mathrm{CDCl}_{3}, 500 \mathrm{MHz}\right): \delta 7.93$ $(\mathrm{d}, J=7.2 \mathrm{~Hz}, 1 \mathrm{H}), 7.58(\mathrm{~d}, J=7.4 \mathrm{~Hz}, 1 \mathrm{H}), 7.55(\mathrm{t}, J=7.6$ $\mathrm{Hz}, 3 \mathrm{H}), 7.33-7.38$ (m, 2H), 7.29-7.24 (m, 2H), 3.88 (s, 3H).

(5-Methoxy-1H-indol-3-yl)-phenyl-methanone (7) ${ }^{6}$. White solid; m.p. $223-225^{\circ} \mathrm{C} ;{ }^{1} \mathrm{H}$ NMR $\left(\mathrm{CDCl}_{3}, 500 \mathrm{MHz}\right): \delta$ $8.47(\mathrm{~d}, J=6.0 \mathrm{~Hz}, 1 \mathrm{H}), 7.84(\mathrm{~d}, J=8.0 \mathrm{~Hz}, 2 \mathrm{H}), 7.58-7.63$ $(\mathrm{s}, 1 \mathrm{H}), 7.46-7.51(\mathrm{~m}, 2 \mathrm{H}), 7.28(\mathrm{t}, J=6.5 \mathrm{~Hz}, 3 \mathrm{H}), 3.88(\mathrm{~s}$, $3 \mathrm{H})$.

(5-Bromo-1 $H$-indol-3-yl)-phenyl-methanone $(\mathbf{8})^{13}$. White solid; m.p. $265-267{ }^{\circ} \mathrm{C}$; ${ }^{1} \mathrm{H}$ NMR $\left(\mathrm{CDCl}_{3}, 500 \mathrm{MHz}\right): \delta 8.38$ $(\mathrm{d}, J=2.0 \mathrm{~Hz}, 1 \mathrm{H}), 8.01(\mathrm{~s}, 1 \mathrm{H}), 7.80-7.76(\mathrm{~m}, 2 \mathrm{H}), 7.63-7.61$ $(\mathrm{m}, 1 \mathrm{H}), 7.52-7.46(\mathrm{~m}, 3 \mathrm{H}), 7.41(\mathrm{~d}, J=8.4 \mathrm{~Hz}, 1 \mathrm{H})$.

1-(1H-Indol-3-yl)ethanone $(9)^{13}$. White solid; m.p. 189$190{ }^{\circ} \mathrm{C} ;{ }^{1} \mathrm{H} \mathrm{NMR}\left(\mathrm{CDCl}_{3}, 500 \mathrm{MHz}\right): \delta 8.22(\mathrm{~d}, J=7.0 \mathrm{~Hz}$, $1 \mathrm{H}), 8.13$ (s, 1H), 7.45 (d, J=7.0 Hz, 1H), 7.23-7.20 (m, 2H), 2.53 (s, 3H).

4-Chlorophenyl (1H-indol-3-yl)methanone $(\mathbf{1 0})^{13}$. Yellowish white solid; m.p. $241-242{ }^{\circ} \mathrm{C}$; ${ }^{1} \mathrm{H} \mathrm{NMR}\left(\mathrm{CDCl}_{3}, 500 \mathrm{MHz}\right)$ : $\delta 8.24(\mathrm{~d}, J=7.5 \mathrm{~Hz}, 1 \mathrm{H}), 7.96(\mathrm{~s}, 1 \mathrm{H}), 7.81(\mathrm{~d}, J=7.5 \mathrm{~Hz}$, $2 \mathrm{H}), 7.60(\mathrm{~d}, J=7.5 \mathrm{~Hz}, 2 \mathrm{H}), 7.54(\mathrm{~d}, J=7.0 \mathrm{~Hz}, 1 \mathrm{H}), 7.33-$ $7.23(\mathrm{~m}, 2 \mathrm{H})$.

$1 H$-Indol-3-yl (4-methoxyphenyl)methanone (11) ${ }^{13}$. Light yellow solid; m.p. $88-89{ }^{\circ} \mathrm{C} ;{ }^{1} \mathrm{H}$ NMR $\left(\mathrm{CDCl}_{3}, 500 \mathrm{MHz}\right): \delta$ 8.23 (d, $J=7.0 \mathrm{~Hz}, 1 \mathrm{H}), 7.94$ (s, 1H), 7.80 (d, $J=7.5 \mathrm{~Hz}, 2 \mathrm{H})$, $7.52(\mathrm{~d}, J=7.0 \mathrm{~Hz}, 1 \mathrm{H}), 7.23-7.21(\mathrm{~m}, 2 \mathrm{H}), 7.05$ (d, $J=7.5$ $\mathrm{Hz}, 2 \mathrm{H}), 3.83$ (s, 3H).

1-(1H-Indol-3-yl)-2,2-dimethylpropan-1-one $(\mathbf{1 2})^{13}$. White solid; m.p. $160-162{ }^{\circ} \mathrm{C} ;{ }^{1} \mathrm{H}$ NMR $\left(\mathrm{CDCl}_{3}, 500 \mathrm{MHz}\right): \delta$ $8.52(\mathrm{~d}, J=7.5 \mathrm{~Hz}, 1 \mathrm{H}), 7.99(\mathrm{~s}, 1 \mathrm{H}), 7.42(\mathrm{~d}, J=7.5 \mathrm{~Hz}, 1 \mathrm{H})$, 7.32-7.28 (m, 2H), $1.41(\mathrm{~s}, 9 \mathrm{H})$.

\section{RESULTS AND DISCUSSION}

The screening of the catalysts was conducted using indole (1a) and benzoyl chloride (2a) as a model reaction. The results are summarized in Table-1, entries 1-9. Among the catalysts examined including conventional Lewis acid, metal oxides and iron containing compound, iron power demonstrated the greatest activity of the catalysts tested in the Friedel-Crafts acylation of indole, in terms of reaction rate and isolated yield. In a typical experiment, indole (1a) was added to a mixture of iron powder and benzoyl chloride (2a). The mixture was stirred at room temperature until the reaction was completed. The product was isolated by simple extraction of the solid mass by ethyl acetate followed by the usual workup. The indole with benzoyl chloride reacted very rapidly within $20 \mathrm{~min}$. We also examined the effect of the solvents toward this reaction (Table1 , entries 10-14). Although the reaction proceeded smoothly in dichloromethane or dichloroethane, only $45 \%$ and $49 \%$ yields of the product were detected. Thus iron powder was found to be the better choice for this reaction. Since the addition order played significant effect tothe synthesis of 3-acylated indoles ${ }^{7}$, we also investigated the effect of reactant addition order. The results demonstrated that in the protocol present here, the addition order of indole, acyl chloride and catalyst did not show important effect to the acylation (Table-1, entries 1,15 and16).

TABLE-1

FRIEDEL-CRAFTS ACYLATION OF INDOL WITH BENZOYL CHLORIDE UNDER VARIOUS REACTION CONDITIONS ${ }^{a}$

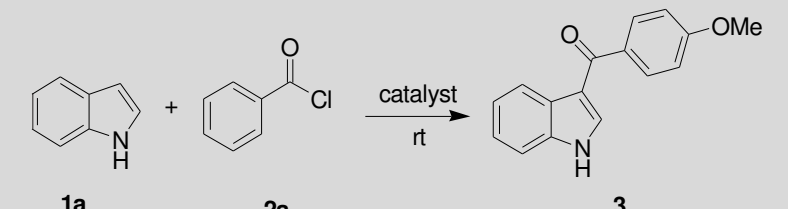

\begin{tabular}{|c|c|c|c|c|}
\hline Entry & Catalyst & Solvent & Time $(\mathrm{h})$ & Yield (\%) \\
\hline 1 & Iron powder ${ }^{c}$ & Neat & 0.3 & 65 \\
\hline 2 & $\mathrm{Fe}_{2} \mathrm{O}_{3}$ & Neat & 8 & 20 \\
\hline 3 & $\mathrm{FeCl}_{3}$ & Neat & 6 & 36 \\
\hline 4 & $\mathrm{FeSO}_{4}$ & Neat & 2 & 52 \\
\hline 5 & $\mathrm{Fe}_{2}\left(\mathrm{SO}_{4}\right)_{3}$ & Neat & 8 & 31 \\
\hline 6 & $\mathrm{ZnO}$ & Neat & 4 & 39 \\
\hline 7 & $\mathrm{ZrO}_{2}$ & Neat & 7 & 18 \\
\hline 8 & $\mathrm{SnO}_{2}$ & Neat & 7 & 15 \\
\hline 9 & $\mathrm{In}_{2} \mathrm{O}_{3}$ & Neat & 12 & 12 \\
\hline 10 & Iron powder & DCM & 1 & 45 \\
\hline 11 & Iron powder & DMF & 3 & 41 \\
\hline 12 & Iron powder & DCE & 1 & 49 \\
\hline 13 & Iron powder & $\mathrm{CH}_{3} \mathrm{CN}$ & 1 & 47 \\
\hline 14 & Iron powder & $\mathrm{CHCl}_{3}$ & 1 & 49 \\
\hline $15^{\mathrm{d}}$ & Iron powder & Neat & 0.3 & 53 \\
\hline $16^{\mathrm{e}}$ & Iron powder & Neat & 0.3 & 40 \\
\hline
\end{tabular}

${ }^{a}$ Reaction condition: Indole $(2 \mathrm{mmol})$, benzoyl chloride $(1.5 \mathrm{mmol})$, catalyst $(2 \mathrm{mmol})$, solvent $(3 \mathrm{~mL})$. Addition order: indole was added to the reaction mixture containing benzoyl chloride and catalyst.

'Isolated yield; ' Mesh number: 80.

dAddition order: benzoyl chloride was added to the reaction mixture containing indole and iron powder.

${ }^{\mathrm{e}}$ Addition order: iron powder was added to the reaction mixture containing indole and benzoyl chloride.

The effect of the catalyst amount and reaction temperature on the yield of the corresponding acylated product was carried out. Thus far, $100 \mathrm{~mol} \%$ iron powder had been used to catalyze the acylation of indole. Indeed, the catalyst concentrations had major influence to the observed yield as shown in Table-2, entries 1-4. In our optimized protocol, $70 \mathrm{~mol} \%$ iron powder was found to be necessary. Increasing the amount of catalyst did not improve the yields, while further reducing the amount of added catalyst to $50 \mathrm{~mol} \%$ decreased the yield obviously. Furthermore, the results (Table-2, entries 2, 5 and 7) revealed that the acylation of indole catalyzed by iron powder depended strongly on the reaction temperature. The reaction proceeded at room temperature favoured the desired acylation. The variation in equivalent of reactants (Table-2, entries 2 and 6) revealed that the 1 equiv of indole and 1.5 equiv of acyl chloride were optimal.

To demonstrate the generality of this method, we set out to explore the scope of the optimized Friedel-Crafts acylation 


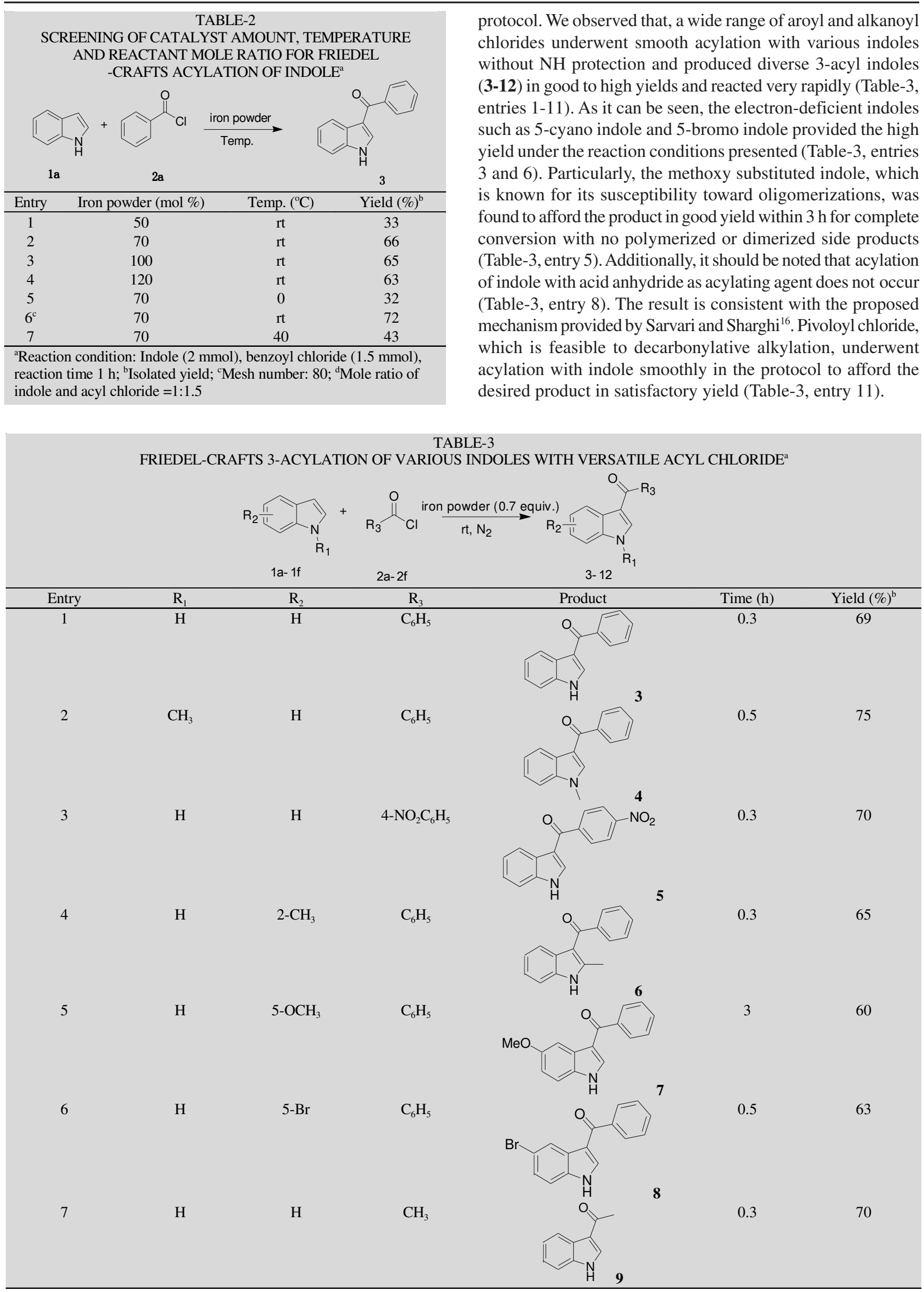




\begin{tabular}{|c|c|c|c|c|c|c|}
\hline Entry & $\mathrm{R}_{1}$ & $\mathrm{R}_{2}$ & $\mathrm{R}_{3}$ & Product & Time (h) & Yield $(\%)^{\mathrm{b}}$ \\
\hline 8 & $\mathrm{H}$ & $\mathrm{H}$ & $\mathrm{CH}_{3}$ & & 24 & 0 \\
\hline 9 & $\mathrm{H}$ & $\mathrm{H}$ & 4- $\mathrm{ClC}_{6} \mathrm{H}_{5}$ & & 1 & 61 \\
\hline 10 & $\mathrm{H}$ & $\mathrm{H}$ & $4-\mathrm{OCH}_{3} \mathrm{C}_{6} \mathrm{H}_{5}$ & & 2 & 66 \\
\hline 11 & $\mathrm{H}$ & $\mathrm{H}$ & $\left(\mathrm{CH}_{3}\right)_{3} \mathrm{C}$ & & 0.5 & 73 \\
\hline
\end{tabular}

\section{Conclusion}

In summary, we have described a novel and highly efficient solvent-free protocol for regioselective Friedel-Crafts acylation of the $\mathrm{C} 3$ position of indolesusing nontoxic and inexpensive iron powder. This synthetic method can be employed to the synthesis of a wide range of 3-acyl indoles without $\mathrm{NH}$ protection. The present approach offers the advantages of clean reaction, simple methodology, short reaction time, high yield, easy purification and economic availability of the catalyst.

\section{ACKNOWLEDGEMENTS}

The authors thank the financial support from Innovation Program of Shanghai Municipal Education Commission No.11ZZ180, Science Foundation of Shanghai Institute of Technology No. YJ2012-29, Program of Local Colleges Ability Building of Science and Technology Commission of Shanghai Municipality No. 11520502600 and Affiliation Program No. LM201247 from Shanghai science and technology achievement transformation Promotion Association.

\section{REFERENCES}

1. G. La Regina, T. Sarkar, R. Bai, M.C. Edler, R. Saletti, A. Coluccia F. Piscitelli, L. Minelli, V. Gatti and C. Mazzoccoli, J. Med. Chem., 52, 7512 (2009).
2. Y.S. Wu, M.S. Coumar, J.Y. Chang, H.Y. Sun, F.M. Kuo, C.C. Kuo, Y.J. Chen, C.Y. Chang, C.L. Hsiao and J.P. Liou, J. Med. Chem., 52, 4941 (2009).

3. S.C. Eyley, R.G. Giles and H. Heaney, Tetrahedron Lett., 26, 4649 (1985).

4. J. Bergman and L. Venemalm, Tetrahedron Lett., 28, 3741 (1987).

5. M.M. Faul and L.L. Winneroski, Tetrahedron Lett., 38, 4749 (1997).

6. K.S. Yeung, M.E. Farkas, Z. Qiu and Z. Yang, Tetrahedron Lett., 43, 5793 (2002).

7. O. Ottoni, A.D.F. Neder, A.K.B. Dias, R.P.A. Cruz and L.B. Aquino, Org. Lett., 3, 1005 (2001).

8. J.H. Wynne, C.T. Lloyd, S.D. Jensen, S. Boson and W.M. Stalick, Synthesis, 2277 (2004).

9. T. Okauchi, M. Itonaga, T. Minami, T. Owa, K. Kitch and H. Yoshino, Org. Lett., 2, 1485 (2000).

10. K.S. Yeung, Z. Qiu, M.E. Farkas, Q. Xue, A. Regueiro-Ren, Z. Yang, J.A. Bender, A.C. Good and J.F. Kadow, Tetrahedron Lett., 49, 6250 (2008).

11. D.M. Ketcha and G.W. Gribble, J. Org. Chem., 50, 5451 (1985).

12. T. Watanabe, A. Kobayashi, M. Nishiura, H. Takahashi, T. Usui, I. Kamiyama, N. Mochizuki, K. Noritake, Y. Yokoyama and Y. Murakami, Chem. Pharm. Bull., 39, 1152 (1991).

13. S.K. Guchhait, M. Kashyap and H. Kamble, J. Org. Chem., 76, 4753 (2011).

14. J.O. Morley, J. Chem. Soc. Perkin Trans. II, 601 (1977).

15. S. Paul, P. Nand, R. Gupta and A. Loupy, Synthesis, 2877 (2003).

16. M.H. Sarvari and H. Sharghi, J. Org. Chem., 69, 6953 (2004). 